\title{
PARA UMA MUSEOLOGIA DO SUL GLOBAL. MULTIVERSIDADE, DESCOLONIZAÇÃO E INDIGENIZAÇÃO DOS MUSEUS ${ }^{1}$
}

\author{
Nuno Porto ${ }^{2}$
}

\begin{abstract}
RESUMO
Neste texto proponho que devemos entender os museus como uma instituição ativa na vida das nossas comunidades, e defendo que a descolonização do conhecimento é um engajamento simultaneamente acadêmico e de cidadania participativa para o qual os museus estão particularmente aptos. Para explicitar este argumento faço uso de uma etnografia do Museu de Antropologia da Universidade da Columbia Britânica em Vancouver, no Canadá, em articulação com as noções de etnografia das ausências e etnografia das emergências, inspiradas pelo trabalho de Boaventura de Sousa Santos. Termino ilustrando o meu argumento com a proposta de uma instalação etnográfica para o Museu Théo Brandão, em Maceió, sobre a Lei da Mordaça, como meta-comentário museológico e estratégia pragmática de oposição ao golpe contra a democracia, em curso no Brasil.
\end{abstract}

\author{
PaLAVRAS-Chave \\ Museologia; Descolonização Etnografia; Multidiversidade; Canadá
}

\section{FORA GLOBAL SOUTH MUSEOLOGY \\ MULTI-DIVERSITY, DECOLONIZATION AND INDIGENIZATION OF MUSEUMS}

\begin{abstract}
I advocate that museums are active institutions in the life of our communities and I argue that the decolonization of knowledge is a simultaneously academic and citizen endeavor to which museums are particularly apt. To develop this argument, I venture into an ethnographic exploration of the University of British Columbia Museum of Anthropology, in Vancouver, Canada, mobilizing the categories of ethnography of absences and ethnography of emergences, inspired in the work of Boaventura de Sousa Santos. I conclude illustrating my argument with a proposal for an ethnographic installation at the Théo Brandão Museum in Maceió, on the 'Muzzle Law', intended both as a meta museological comment and as a pragmatic civic strategy of opposition to the coup against democracy currently unfolding in Brazil.
\end{abstract}

KEYWORDS

Museology; Decolonization; Ethnography; Multi-diversity; Canada

\begin{abstract}
1 A apresentação desta conferência pode ser visionada em https://www.youtube.com/watch?v=WODMmWKfImg. Para a presente versão acrescentei - a título de retribuição pela hospitalidade dos organizadores da REA / ABANNE - uma proposta de exposição com a qual se pretende colocar, na prática, o que poderá ser um projeto museológico do sul global. Essa seção do texto, o projeto, leva em consideração o momento presente da sua redação: os finais do mês de Maio de 2016.
\end{abstract}

${ }^{2}$ Universidade da Columbia Britânica - Museu de Antropologia nuno.porto@ubc.ca

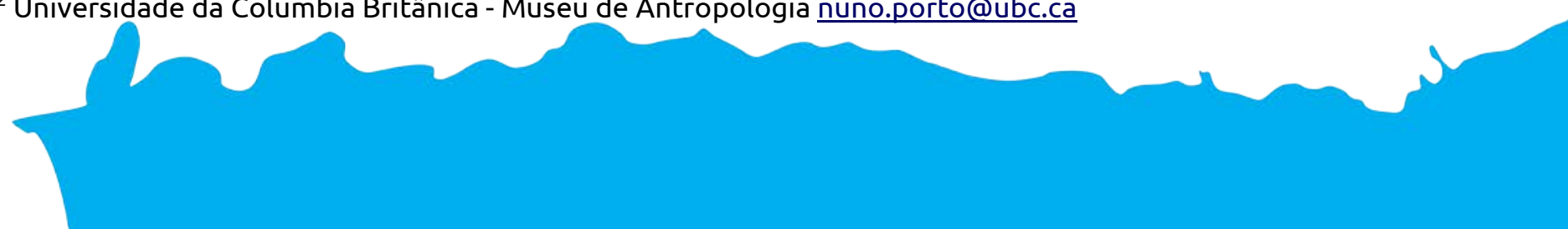




\title{
PaRa la Museología SuR Global. \\ MULTIVERSIDAD, DESCOLONIZACIÓN Y DE MUSEOSAUTOCTONOS
}

\begin{abstract}
RESUMEN
En este texto propongo que debemos interpretar a los museos como una institución activa en la vida de nuestras comunidades, defendiendo que la descolonización del conocimiento es un compromiso tanto académico como de ciudadanía participativa, para el cual los museos se encuentran particularmente aptos. Рara explicitar este argumento, utilizo una etnografía sobre el Museo de Antropología de la Universidad de la Columbia Británica en Vancouver (Canadá), en articulación con las nociones de "etnografía de las ausencias" y "etnografía de las emergencias" inspiradas en el trabajo de Boaventura de Sousa Santos. Termino ilustrando mi argumento con la propuesta de una instalación etnográfica para el Museo Théo Brandão (Maceió, Brasil) sobre la llamada "Ley de la mordaza", como meta-comentario museológico y estrategia pragmática de oposición al golpe contra la democracia que se está llevando a cabo en el Brasil.
\end{abstract}

\author{
PALAVRAS-CLAVE \\ Museología; Descolonizacíon; Etnografia; Multidiversidad; Canadá
}

\section{POUR UNE MUSÉOLOGIE DU SUD GLOBAL. MULTIDIVERSITÉ, DÉCOLONISATION ET DES MUSÉESAUTOCHTONES}

\begin{abstract}
RÉSUMÉ
Dans cet article, je propose que nous devions comprendre le musée comme une institution active dans la vie de nos collectivités. Dans ce sens, je crois que la décolonisation de la connaissance doit être, à la fois, une façon de promouvoir des engagements citoyens et académiques, dans lesquels les musées sont particulièrement appropriés. Pour expliquer cet argument, je fais usage d'une ethnographie du Musée d'anthropologie, de l'Université de la Colombie-Britannique (Vancouver, Canada). Je m'inspire des notions de "l'ethnographie d'absence » et de "l'ethnographie des situations d'urgence", retirés du travail de Boaventura de Sousa Santos. Je conclu mes proposition en illustrant mon argumentation avec la proposition d'une installation ethnographique pour le Musée de Anthropologie et Folklore Theo Brandão, situé à Maceio, et sur la « Gag Rule ». Il s'agit d'un méta-commentaire et stratégie pragmatique de l'opposition au coup d'État contre la démocratie en cours au Brésil.
\end{abstract}

\section{MOTS-CLÉS}

Muséologie; décolonisation; ethnographie; multi-diversité; Canada 
As questões decorrentes do reconhecimento de direitos diferenciados, dos conflitos associados a esse reconhecimento e suas relações axiais com a assunção da pluralidade de saberes, têm vindo a constituir-se como questões centrais para a museologia crítica contemporânea. Na verdade, pode afirmar-se que elas resultam do entrosamento de práticas coloniais na instituição das modalidades operativas dos museus, incluindo os procedimentos, a colocação dos agentes e as relações integrantes de cadeias de recolha, inventário, catalogação, conservação, exposição e arquivo de objetos.

No momento presente, a atuação com base a estas questões não é um exclusivo dos profissionais de museus, já que elas provêm do público, das comunidades de colaboração com os museus e, muito significativamente, de práticas artísticas contemporâneas.

Com base em casos concretos, partindo da metáfora do Sul Global (proposta por Boaventura de Sousa Santos), argumento que a abordagem destas questões exige a afinação de práticas museológicas socialmente engajadas; que estas têm por base relações sociais localizadas no tempo e no espaço; consequentemente, dado que diferentes contextos suscitam diferentes abordagens, elas não seguem um figurino único; que essas práticas devem assumir um projeto de multiversidade de saberes e práticas; finalmente, que modalidades de descolonização institucional devem decorrer em articulação com modalidades de indigenização dos museus.

\section{CONTEXTO: EPISTEMOLOGIAS DO SUL}

Рara entrar no tema desta fala de hoje eu gostaria de esboçar uma plataforma comum a propósito da noção de sul global (que está no título) tomada do trabalho do sociólogo Boaventura de Sousa Santos e que é uma metáfora que ele desenvolve no âmbito da sua proposta de pensar a história recente como um processo de epistemicídio - isto é - um processo de empobrecimento do mundo em termos de formas de conhecimento e de experiências do mundo relacionadas a essa diversidade de saberes e experiências. Nesta leitura - por favor notem que estou fazendo uma simplificação com o propósito de partir de uma plataforma comum: o sul de que fala Sousa Santos não é o sul geográfico. O Sul é uma metáfora para referenciar as vítimas de relações de poder Norte - Sul, e as respectivas formas de conhecimento que é são urgentes resgatar. E, neste sentido - e passo a citar - "as epistemologias do sul são um conjunto de procedimentos que visam reconhecer e validar o conhecimento produzido - ou a produzir - por aqueles que têm sofrido sistematicamente as injustiças, a opressão a dominação, e a exclusão, causadas pelo capitalismo, pelo colonialismo e 
pelo patriarcado". (Santos, 2011) E é - acrescenta o autor - um conhecimento na perspectiva desses sujeitos, um conhecimento nascido na luta. Neste sentido também, podemos falar do Sul no Norte - a propósito, por exemplo, das populações indígenas vítimas dos processos de colonização interna associadas aos processos de constituição dos estados nacionais. E, simetricamente, podemos falar de um norte no Sul: caso do Brasil, com certeza.

Em síntese, este Sul é um sul político, um sul nas relações de poder. A recuperação programática deste sul como agente da história requer dois tipos de exercícios complementares a que Sousa Santos chama - primeiro - a sociologia das ausências - ou seja uma sociologia das práticas, saberes e experiências que foram sendo tornadas invisíveis pelos processos de dominação e exclusão - e a sociologia das emergências, isto é, uma atenção privilegiada às experiências de resistência e criatividade do sul face ao norte amplificando e dando voz, conferindo cidadania, a novas práticas, saberes e experiências provenientes do sul global.

Quando eu sugiro no título desta fala uma espécie de programa para uma museologia do sul global é do sul entendido neste sentido. E dito isto - e sem mais explicação - vou assumir que as coleções etnográficas podem ser instrumentos cruciais tanto numa etnografia das ausências quanto numa etnografia das emergências. E para entrar no tema começo por exemplos do museu onde trabalho, argumentando com base em casos que ilustram a presença, no norte, do Sul global.

\section{MOA (MUSEUM OF ANTHROPOLOGY)}

O museu onde eu trabalho fica situado em Vancouver, na costa noroeste do Pacífico, no Canadá. Na versão para turista o MOA é uma atração imperdível quando se visita a cidade. Fundado nos anos quarenta e dotado de um novo edifício em 1976 o museu foi atualizado entre 2001 e 2010. Aos turistas ele é apresentado como

"o museu canadense contemporâneo de artes e culturas do mundo, um lugar de beleza arquitetônica extraordinária, de programas desafiantes e exposições instigantes (...) oferecendo oportunidades infindáveis para o visitante aprender a sua própria e outras culturas" 3 .

Uma vez chegado ao museu o turista acidental poderá ficar a saber mais alguns detalhes, designadamente que o MOA e todo o campus universitário onde o museu se encontra, está situado em território "tradicional, ancestral e não cedido" reclamado pelo grupo indígena Musqueam, e que, desde 2010 (após a renovação do MOA), a entrada no museu é uma performance que segue o protocolo de boas vindas dos Musqueam: as portas Haida foram

\footnotetext{
${ }^{3}$ http://www.moa.ubc.ca
} 
removidas para o interior e todo o primeiro contato com o museu (tanto no exterior como no interior) é assegurado pela cultura material Musqueam4

Estas duas versões são coexistentes e o fato do museu estar situado em terra indígena - bem como a universidade e, já agora, a cidade - não parecem ser suscetíveis de constituir tema de atração turística embora constitua um aprendizado inevitável da visita ao museu. A perspectiva sobre 'culturas do mundo' é, portanto, ancorada numa colocação local, ancorado num lugar de enunciação (na acepção de Mignolo5): o mundo é visto a partir do Noroeste do Pacífico, essa faixa situada entre o Pacífico e as Montanhas Rochosas, onde os colonos do século 19 achavam que estavam tão longe dos centros de decisão que consideraram desnecessário fazer tratados com as populações indígenas. Os tratados estão sendo negociados hoje em dia. $O$ mundo é visto desta possibilidade de reclamar - através da reclamação da terra - a identidade, a memória e a agencialidade. O conceito de multiversidade - aplicado às galerias de exposição permanente - dialoga com este processo.

\section{MULTIVERSIDADE}

A noção de multiversidade tem vindo a ser desenvolvida desde finais dos anos 90, pelo ugandês Paulo Wongoola e pelo goês Claude Alvares com o objetivo programático de instituir alternativas ao pensamento único ocidental. Para Claude Alvares, “a ideia de multiversidade baseia-se na realidade firme da existência de universos diversos de percepção, cosmologias específicas e distintos corpos de conhecimento válido" ${ }^{6}$. A ideia de multiversidade constitui-se contra a noção segundo a qual o conhecimento científico - e apenas esse tipo de conhecimento - é a única forma de saber válida, mas constitui-se também propondo alternativas ao modo dominante de transmissão de saber - a universidade. Note-se que esta instituição ( $a$ Universidade) é, para ambos os autores, entendida como parte integrante do projeto colonial que a noção e a prática da multiversidade pretendem desmontar (desmontar e não apenas desconstruir, é desmontar no sentido de tornar aquilo que existe em algo que não existe mais) ${ }^{7}$.

\footnotetext{
${ }^{4}$ http://www.musqueam.bc.ca

${ }^{5}$ Walter Mignolo (2003), faz a distinção entre perspectiva e lugar de enunciação. A perspectiva “[...] não é o produto da dor e da raiva dos despossuídos em si, mas sim de quem, mesmo não sendo despossuído, assume a perspectiva desses" (MIGNOLO, 2003, p. 28). Já o lugar de enunciação refere-se a lugares de história, de memória, de dor, de línguas e de saberes diversos.

${ }^{6}$ http://www.swaraj.org/multiversity/ideamultiversity.htm

${ }^{7}$ Mpambo, a Multiversidade africana é o filho coletivo primogênito dos trabalhos intelectuais de várias centenas de estudiosos africanos, líderes sociais e ativistas em uma série de reflexões estratégicas,
} 
O projeto Mpambo - a não-universidade - é baseado em conhecimento e nas línguas tradicionais coordenado por Paulo Wongoola no Uganda.

1. No MOA as galerias da multiversidade são trabalho em curso e pretendem valorizar as coleções como produto de universos culturais específicos, válidos por si próprios, coexistentes no mundo em que vivemos. São galerias contra o epistemicídio ancorando o projeto museológico na noção segundo a qual qualquer visitante - independentemente da proveniência, idade, identidade de gênero, étnica ou outra - é um pesquisador. Em consequência o espaço está equipado com quatro salas de pesquisa que são franqueadas aos interessados em fazer pesquisa com objetos ${ }^{8}$, e de várias estações informáticas que disponibilizam toda a informação de catálogo sobre as coleções 9 .

Esta política de catálogo aberto faz parte da assunção segundo a qual o conhecimento que o museu detém é parcial e, assumidamente, incompleto e temporário. Os visitantes são incentivados a comunicar quaisquer reparos que tenham a fazer sobre a descrição das peças e, ao longo dos últimos 40 anos, essa relação tem permitido melhorar a informação disponibilizada ao publico tanto no catálogo quanto nas exposições permanentes.

2. Um segundo elemento integral a este entendimento do catálogo como repositório de informação susceptível, por definição, de melhoramento tem sido o desenvolvimento da Rede de Pesquisa Recíproca ${ }^{10}$. Estabelecida por meio de uma parceria entre o MOA, os Musqueam, a Nação Stó:lō e o centro U'mista dos Kwakwaka'wakw, a rede teve por propósito inicial: a) criar uma plataforma de acolhimento das coleções da Costa Noroeste dispersas por diferentes instituições dentro e fora do Canadá; b) permitir a identificação, descrição e reclassificação das coleções segundo distintas perspectivas indígenas capazes de habilitar as possibilidades comparativas da catalogação de museu. Parcialmente, portanto, o trabalho de catalogação é um trabalho de exploração intercultural (no sentido de desenvolver categorias de classificação de

consultas formais, informais e não-formais, durante um período de oito anos (iniciados em 1990), com a solidariedade dos estudiosos, líderes sociais, ativistas, amigos e simpatizantes de todos os continentes do mundo. Os participantes vêm de todos os níveis de esferas da vida, dos sectores público e privado, bem como da sociedade civil. São pessoas que têm estado ativas a nível local, nacional, regional e global, em áreas políticas, técnicas ou operacionais. Pertencem a um largo espectro de filiações políticas e ideológicas mas estão unidos na crença e na procura de uma África com capacidade de determinar o seu destino no pós guerra fria. Mpambo, a multiversidade africana, captura e cristaliza vários milhares de horas de reflexão enraizados nas práticas, experiências, memórias, esperanças e aspirações populares. (Wongoola, 2012)

${ }^{8}$ Texteis, Cerâmica, Etnografia e Objetos culturalmente sensíveis.

${ }^{9}$ http://collection-online.moa.ubc.ca

${ }^{10}$ https://www.rrncommunity.org 
objetos baseadas em entendimentos indígenas e não indígenas tornados mutuamente inteligíveis).

3. Um terceiro elemento das galerias consiste no esforço deliberado de sensibilizar o público para a noção segundo a qual a cultura é um conceito que se aplica a realidades em permanente mudança decorrente de relações de diferente natureza e intensidade. Nesta fase, a tentativa recai sobre a demoção da ideia de área cultural em favor da noção de áreas de troca e zonas de circulação e interação que são representadas nos oceanos. A entrada nas galerias fazse pelo Pacífico Norte, baixa ao Pacífico Sul, daí para o Oceano Indico, o Atlântico e, de novo ao Pacífico. Nas visitas guiadas a tónica sobre a fluidez, as trocas, os intercâmbios é facilitada por esta opção na distribuição das coleções. E uma das formas de sublinhar a natureza entrosada em múltiplos intercâmbios dos objetos faz-se, em grande medida, recorrendo à arte contemporânea ${ }^{11}$.

\section{GUERRILHA}

O passo seguinte ilustra este processo. No MOA o planejamento da exposição "permanente" nas galerias da multiversidade levantou - e mantém de pé - o debate sobre modalidades de implicação das coleções etnográficas no comentário a assuntos correntes sejam eles de natureza museológica - por exemplo: novas aquisições do museu, sejam eles de natureza política. No fundo debatemo-nos com a possibilidade real de, por um lado, pretender que múltiplas formas de conhecimento são necessárias para lidar com problemas contemporâneos e, simultaneamente e em contradição com esse princípio, anular tecnicamente qualquer possibilidade de fazer as coleções atuar em favor de uma etnografia das emergências. A solução que temos vindo a praticar consiste no uso das vitrines de topo (que abrem ou fecham seções internas das Galerias de Multiversidade) como "vitrines de guerrilha", uma designação interna e - tanto quanto sei - informal (nunca li esta designação escrita em nenhum documento oficial).

Anoto, de passagem, a semelhança de intenções com o que Gustavo Buntinx e Ivan Karp chamaram de "museologias tácitas" que têm como atitude uma "posição de guerra" (no sentido Gramsciano) cujo propósito é a produção de fricções com o senso comum em vigor ou em vias de consensualização. Vou exemplificar este processo com duas instalações atualmente em curso: Hawilmis - Tesouro de um Chefe e Uma mente, Um coração (One Mind, One Heart).

Uma mente, Um coração é uma instalação com curadoria de Pam Brown em parceria com representantes da Nação Heiltsuk à qual ela pertence. A instalação consiste na resposta dos

\footnotetext{
${ }^{11}$ Sob inspiração entre outros, do trabalho de Fred Wilson em 1991, Baltimore.
} 
Heiltsuk à proposta de construção de um oleoduto pela empresa petrolífera Enbridge que atravessaria o seu território e as suas águas pesqueiras. O movimento de contestação Heiltsuk é o centro da instalação narrando, cronologicamente e por meio de fac-símiles da documentação produzida, todos os passos que foram dados pelas lideranças e pelas comunidades, que conduziram ao repúdio público e unânime - uma mente, um coração - do projeto. O museu encomendou ao jovem artista e ativista Heiltsuk, Nusi lan Reid uma peça de arte que refletisse sobre o assunto. Nusi lan Reid trouxe para a contemporaneidade uma representação do guardião ancestral Yagis, devorando um petroleiro que havia invadido as águas territoriais tradicionais. Obviamente que, ao associar-se à Nação Heiltsuk neste protesto, o museu toma uma posição não isenta de riscos que torna também manifesta ao seu público e aos seus membros, pelo que este tipo de iniciativas é ponderado caso a caso e requer um consenso alargado entre o pessoal do museu. Digamos que não é o tipo de atitude que nos faz ficar nas boas graças de um núcleo significativo de potenciais patrocinadores.

Hawilmis - Tesouro de um Chefe, com curadoria de Karen Duffek, está baseada numa doação de um artefato que teria pertencido ao Capitão James Cook e que teria sido obtido pelo próprio em finais do século XVIII um pouco a norte de Vancouver. Mais de duzentos anos depois, a peça emergiu num leilão, onde foi adquirida por um benfeitor que a ofereceu ao museu. $\mathrm{O}$ museu contactou os representantes dos Nuu-chah-nulth-aht. Na ocasião da cerimónia de doação, membros do Conselho Tribal Nuu-chah-nulth-aht deslocaram-se ao MOA para receber o objeto. Nessa ocasião elaboraram um texto que acompanha a exposição da peça. Nele, os Nuuchah-nulth-aht contemporâneos explicam a circulação do seu objeto como parte do seu entendimento da viagem de James Cook. Claramente, nesta perspectiva, a viagem de James Cook até à costa Noroeste do Pacífico teve por propósito colocar os ingleses em contato com os Nuu-chah-nulth-aht, cuja fama os havia tornado anteriormente conhecidos em Inglaterra. E o resto da viagem de Cook teve por objetivo expandir a fama, merecida, dos Nuu-chah-nulth-aht pelos quatro cantos do mundo. A repatriação do objeto é, portanto, normal, uma vez que as tecnologias contemporâneas não necessitam mais deste tipo de objeto para colocar os Nuuchah-nulth-aht no centro das atenções mundiais, e o objeto pode, assim, retornar à Costa Noroeste na condição de um diplomata muito viajado que merece, agora, repousar.

\section{DESCENTRAMENTO}

A política de catálogo aberto e a assunção programática da ideia de multiversidade, coexistem e, num certo sentido, definem as condições de possibilidade das intervenções mais 
pontuais - como estas de guerrilha - em articulação com a programação das exposições temporárias ${ }^{12}$.

Mas gostaria de argumentar que para construir uma museologia que se posiciona no sul global é necessário assumir para o museu uma posição de descentramento, isto é - e admito que esta posição está em total a-sintonia com a maioria dos estudos de museu - assumir que o museu é apenas uma parte de uma configuração mais ampla que é suscetível de ser pensada como policêntrica; nessa configuração, em segundo lugar, o desafio consiste em interpretar as modalidades de relação nas quais o trabalho museológico se constitua num valor acrescentado.

Рara concretizar o que pretendo dizer, deixem-me explicitar que nenhuma das instalações de que falei antes teria tido condições de possibilidade noutra configuração, nem teria tido o mesmo tipo de efeito. Ou, dito de outra maneira - e esse é o ponto que estou advogando - o trabalho museológico não vale em si mesmo, mas vale apenas na rede de relações em que o museu participa e que são, obviamente, muito variáveis de uma instituição para outra. No caso concreto estas duas instalações fazem sentido no MOA porque: a) o MOA é dos poucos museus universitários que sobram na América do Norte, coexiste com instituições aparentadas na cidade - nomeadamente o Museu de Vancouver (municipal) e o Museu de Arte; b) desde 1976 que tem vindo a advogar como arte 'tout court' as artes indígenas contemporâneas; c) numa província, ainda chamada de Colúmbia Britânica, onde não houve tratados com as populações indígenas e onde esse processo está em curso, d) num momento da história em que o Estado canadense reconhece e condena, por um lado, as políticas de extermínio cultural do passado e, por outro, prossegue - por outros meios - esse mesmo tipo de política. Nada mais exemplificativo desta dualidade que o patrocínio dado à Comissão para a Verdade e Reconciliação ${ }^{13}$ - por um lado - e a atuação repressiva que favoreceu a emergência e consolidação do movimento Idle No More, Não Mais Quietos, formado em contestação das políticas discriminatórias do Estado Canadense. O movimento foi fundado em Dezembro de 2012 e foi inspirado pela greve de fome da chefe Theresa Spence da nação Attawapiskat, em contestação à aprovação de uma lei (a Lei C-45) pelo governo conservador de Stephen Harper, que acaba com obrigatoriedade de consulta às Primeira Nações sobre a construção ou instalação de equipamentos em terras e cursos de água. Ou seja, a lei é uma carta branca ao lobby petroleiro para instalação de oleodutos até à costa do pacífico. Perante a recusa de Harper

\footnotetext{
${ }^{12} \mathrm{O}$ museu tem duas galerias de exposições temporárias. Uma delas assegura uma exposição por ano e a outra galeria assegura mais duas.

${ }^{13}$ http://www.trc.ca
} 
em receber Theresa Spence, ela entrou em greve de fome, até que Harper cedeu à sua demanda.

A Comissão para a Verdade e Reconciliação do Canadá teve por objeto central o sistema de Escolas Residenciais e a condenação explícita do genocídio cultural intrínseco à sua implantação. A Comissão debruçou-se também sobre as sequelas presentes e formas de as mitigar. As Escolas Residenciais foram instituídas sob a ideia da geração perdida: procurando integrar as populações indígenas como parte da nação canadense, o objetivo confesso das escolas era 'matar o índio na criança'. Рara esse efeito as crianças eram separadas do meio familiar e comunitário entre os 6 e os 16 anos. Sendo responsabilidade do Estado elas eram geridas - em regime de delegação - por diferentes Igrejas. Nas conclusões dos seus trabalhos a Comissão para Verdade e Reconciliação calcula em 40.000 as crianças mortas vítimas de inúmero tipo de violências diretas. Os sobreviventes das Escolas Residenciais sairiam, na melhor das hipóteses, com habilitação para serem mão de obra barata e revestirem a base da pirâmide social canadense. Muitas das comunidades de onde haviam partido desapareceram na sua ausência.

O exemplo das Escolas Residenciais é frequentemente invocado para falar de cultura como essencial à saúde e bem estar, posição que supera (mais do que contraria) a oposição cartesiana entre corpo e mente, matricial no pensamento ocidental, e ilustra um último ponto desta apresentação, sobre as relações entre descolonialidade e indigenização.

\section{DESCOLONIZAR O MUSEU}

Tem vindo a produzir-se uma literatura relativamente ampla que tende a enfatizar como uma nova doxa museológica o projeto de descolonizar o museu, proveniente de vários quadrantes mas com particular incidência prática no sul global do espaço imperial Britânico, designadamente a Nova Zelândia e a Austrália. Uma corrente inicial é focada no que poderíamos qualificar como uma curadoria das emergências ao prestar atenção a novos projetos artísticos fundados em expressões tradicionais e partindo destes como fundamento da revisão dos modos de exposição permanente que inclui a destituição de taxonomias vigentes e a adopção de gramáticas e terminologias não canónicas, engajadas em projetos participativos. A coleção kwakwaka'wak do MOA é um exemplo deste processo: as máscaras estão dispostas não mais por critérios morfológicos mas por sua ordem de entrada no potlatch; alguns objetos foram reconfigurados como pertences familiares e instalados em consonância com essa proveniência 
e, neste caso, todos eles foram intervencionados para proteger o público que vem vê-los da sua energia excessiva (por isso estão amarradas).

A distinção entre descolonizar e indigenizar comporta uma mudança de centralidade, na qual o processo colonial - na sua forma efetiva ou enquanto lastro histórico institucionalmente manifesto - é deixado de lado e tornado passado em favor de práticas dirigidas a procurar respostas para questões comuns, articulando modalidades etnográficas das ausências em etnografias das emergências. Esse gesto mobiliza o que resta do museu no decurso da crítica descolonial em prol de projetos que são pensados não em função da instituição mas sob promoção das pessoas cujas vidas e cujas lutas podem se beneficiar do trabalho do museu que deixa, neste processo, de ser mais uma instituição colonial para exercício alcatifado do poder dominante para se assumir como instituto de criação do reconhecimento das alternativas existentes ao capitalismo, ao colonialismo e ao patriarcado. Este exercício pode partir de trabalho museológico canônico, como aquele que identificamos com projetos centrados em coleções, mas comporta várias nuances que favorecem a transição de uma metodologia expositiva onde os objetos são usados como materializações de uma afirmativa para ser deliberadamente instalados como objetos-questões. Ou seja, transitar de um mostra e conta para um mostra e questiona. Em síntese, este movimento articula-se em três pólos: ele parte de uma noção de multiversidade cultural, implica assumir uma política de catálogo aberto e move-se na direção de instituir o museu como um nó relacional.

Tentarei ilustrar este movimento mediante o projeto de uma exposição. Dado que esta reunião decorre em Maceió, permitam-me que retribua a hospitalidade da organização sugerindo uma instalação para o Museu Théo Brandão de Antropologia e Folclore, um espaço cultural de referência em Alagoas. Neste projeto procurarei articular os princípios defendidos na seção primeira da minha comunicação que aqui se encerra.

\section{PROJETO OU MORDAÇA: INSTALAÇÃO ETNOGRÁFICA}

O objetivo desta instalação ${ }^{14}$ é criar um espaço de diálogo sobre aquilo que parece ser uma questão central no Brasil em ambiente de golpe institucional em curso: o da ameaça objetiva às liberdades individuais elementares dos cidadãos da união pelo desprezo do texto legal que é delas garantia, a Constituição brasileira. Enquanto em Brasília o evento-ícone do desconchavo em curso será, provavelmente, o exercício de degradação da dignidade humana que foi a votação do impeachment da Presidenta do Brasil (elucidando a capacidade de atingir

\footnotetext{
${ }^{14}$ A noção de instalação etnográfica, distintamente da ideia de exposição sugere este trensito de uma etratégia expositiva de mostra-e-conta para uma estratégia de mostra-e-questiona. Ver Porto(2007).
} 
de novas metas, subterrâneos, de baixaria que também qualificam como Baixa essa Câmara), o projeto de Lei da Escola Livre, popularmente apropriado como Lei da Mordaça, constitui um exemplo local deste processo, e daí a sua eleição como tema da instalação, explorando a hipótese de que um tema local do Estado de Alagoas (a chamada Lei da Mordaça) possa constituir-se na base de uma plataforma para debater questões nacionais (a ameaça à democracia pelo golpe institucional em curso neste mês de Maio de 2016), ou mesmo globais - a relação entre educação e desenvolvimento.

Alagoas é um dos estados mais pobres do Brasil, o que contribui para a manutenção do Índice de Desenvolvimento Humano mais baixo do país (ao nível do Gabão, na África Ocidental), bem como do menor índice de alfabetização, o qual, do ponto de vista funcional excede os 50\% da população. A agropecuária é a base da economia do Estado, assente numa estrutura agrária definida por grandes latifúndios e largamente responsável pela extrema desigualdade económica da sua população. Em 2006, dos 123.331 estabelecimentos rurais do Estado, aproximadamente 96.000 seriam menores que 10 hectares, constituindo cerca de $10 \%$ do total da área agrícola do Estado. Ou, dito de outra maneira, 90\% das terras estão concentradas na posse de umas poucas famílias e resultam, historicamente, da ocupação de terras indígenas, (às quais se juntaram também terras de quilombos) tradicionalmente dedicadas à produção de açúcar em regime de plantação.

\section{A INSTALAÇÃO}

O centro da instalação é ocupado por uma mordaça de escravo africano do século XIX, próxima, por exemplo, da mordaça documentada na gravura de Jacques Étienne Arago de 1839, intitulada Castigo de Escravo. A proposta de usar uma mordaça deste tipo é deliberada, e decorre da sua remissão à representações populares da Escrava Anastácia enquanto sujeito histórico e entidade de culto. Trata-se de uma remissão para possibilidades semânticas de associar o presente ao passado e à narrativas de preserverança motivadas por noções de senso comum de justiça humana. Em lugar da mordaça ser colocada num sujeito humano, ou uma sua representação figurativa, ela seria colocada num exemplar do texto da constituição brasileira, em sintonia com o sentimento popular relativamente à lei.

\section{PROGRAMA DE PESQUISA E DE RELAÇÃO}

Dentro do programa de um catálogo aberto, a instalação poderia atuar como dispositivo de pesquisa em curso, suscitando o depósito em museu - nas suas coleções ou de 
outra forma - de outra cultura material relacionada com a escravatura e que possa encontrar-se dispersa por entidades privadas no Estado de Alagoas. Paralelamente, no mesmo espaço da instalação, em diálogo com ela e proporcionando um contexto de entendimento da lei como instrumento de silenciamento, facultar-se-ia a evolução histórica dos índices de literacia do Estado, por comparação com o resto da União, descriminados por gênero, classe etária, identidade étnica, por relação com renda, etc. A instalação poderia, finalmente, incluir a memória histórica local relacionada com abordagens pedagógicas alternativas, incluindo os trabalhos do próprio Théo Brandão, designadamente o trabalho intitulado Folclore e educação infantil.

Do ponto de vista curatorial, a instalação abrir-se-ia a múltiplas agências e participações, estabelecendo-se como um projeto de catálogo aberto que decorreria sob o signo da construção de diferentes relações com comunidades locais. Seria, assim, possível partir de um assunto polêmico, demonstrando a possibilidade de criar saberes e memórias coletivas e transformando a mordaça no seu contrário: ou seja, num exercício que lida com a complexidade da multiplicidade de perspectivas solicitando a celebração do livre pensamento e do discurso sem censuras como moeda corrente do desenvolvimento e da democracia que, em si mesmo, se constitui em alternativa aos modelos ditados pelo capitalismo, pelo colonialismo e pelo patriarcado. 


\section{REFERÊNCIAS BIBLIOGRÁFICAS}

ALVARES, Claude, Launching the Multiversity. http://www.swaraj.org/multiversity/ideamultiversity.htm Acesso em: maio/2015.

BUNTIX, Gustavo e KARP, Ivan. Tactical Museologies. In KARP, I., KRATZ, C., SZWAJA, L \& YBARRA-FRAUSTO (eds.), Museum Frictions. Durham: Duke University Press, 2006, p 207-218

MIGNOLO, Walter. Un paradigma otro: colonialidad global, pensamiento fronterizo y cosmopolitismo crítico. In: Historias locales-diseños globales: colonialidad, conocimientos subalternos y pensamiento fronterizo. Madrid: Akal, 2003, p. 19-60

PORTO, Nuno. From Exhibiting to Installing Ethnography: Experiments at the Museum of Anthropology of the University of Coimbra (Portugal) 1999-2005. In BASU, P. \& MACDONALD, S. Exhibition Experiments, Nova York, Londres: Blackwell Publishing, 2007, p.175-196

SOUSA SANTOS, Boaventura. Épistémologies du Sud. Études Rurales, 1/2011, n.187, p. 21-49, 2011.

WANG00LA, Paulo. Mpambo African Multiversity: Dialogue and Building Bridges across Worldviews, Cultures and Languages. In: HENDRY, J. \& FITZNOR, L.. Anthropologists, Indigenous Scholars and the Research Endeavour Seeking Bridges Towards Mutual Respect. Nova York: Routledge,2012 p.28-42

WILSON, Fred. Mining the museum: an installation by Fred Wilson. Baltimore:Contemporary Museum, 1994.

\section{REFERÊNCIAS VIRTUAIS}

Collection online MOA. - collection-online.moa.ubc.ca-Acesso em junho/2015.

Museum of Anthropoloy (MOA) - www.moa.ubc.ca - Acesso em junho/2015.

Musqueam - a living culture - www.musqueam.bc.ca Acesso em junho/2015.

Reciprocal Research Network - www.rrncommunity.org Acesso em junho/2015.

Truth and Reconciliation - www.trc.ca Acesso em junho/2015. 